Meta

Journal des traducteurs

Translators' Journal

\title{
Rodeur ou rodoir
}

\section{Jean-Paul Sénécal}

Volume 11, numéro 2, juin 1966

URI : https://id.erudit.org/iderudit/010465ar

DOI : https://doi.org/10.7202/010465ar

Aller au sommaire du numéro

Éditeur(s)

Les Presses de l'Université de Montréal

ISSN

0026-0452 (imprimé)

1492-1421 (numérique)

Découvrir la revue

Citer ce document

Sénécal, J.-P. (1966). Rodeur ou rodoir. Meta, 11(2), 62-62.

https://doi.org/10.7202/010465ar

Ce document est protégé par la loi sur le droit d'auteur. L’utilisation des services d'Érudit (y compris la reproduction) est assujettie à sa politique d'utilisation que vous pouvez consulter en ligne.

https://apropos.erudit.org/fr/usagers/politique-dutilisation/
Cet article est diffusé et préservé par Érudit.

Érudit est un consortium interuniversitaire sans but lucratif composé de l’Université de Montréal, l'Université Laval et l'Université du Québec à Montréal. Il a pour mission la promotion et la valorisation de la recherche. https://www.erudit.org/fr/ 


\section{Problemes el solutions}

\section{RODEUR OU RODOIR}

Dans le vocabulaire technique, il semble difficile, parfois, au Canadien français de trouver ce que permet le bon usage de la langue du métier.

La recherche de l'expression juste en traduction donne cependant lieu à de fructueuses recherches. Tel fut le cas dernièrement du mot anglais grindingtool ${ }^{1}$. Le dictionnaire Cassell donnait «broyeur» ou "polisseur». Lequel fallait-il choisir? Pourtant ce même dictionnaire, au mot français rodoir ${ }^{2}$ donne bien grinding-tool!

Par sa nature, le rodoir - outil pour roder $^{3}$ - ne peut servir ni à broyer ni à polir. Il semble donc qu'on doive rejeter «broyeur» ou «polisseur» proposés par Cassell.

Par contre, dans l'usage courant des techniciens rodeur coexiste avec rodoir. Cette coexistence pose une nouvelle difficulté.

D'après une enquête très incomplète, il semble que rodeur est très usité chez les machinistes canadiens-français - tant pour le travail du bois que pour le travail du métal. Non seulement rodeur est très courant, mais il est à peu près le seul concurrent du mot anglais.

Les dictionnaires Robert et Bélisle ne font aucune mention de rodeur qu'on retrouve pourtant en toutes lettres dans un dictionnaire technique ${ }^{4}$. La caution de ce dictionnaire devrait-elle suffire à sanctionner l'usage de nos techniciens?

JeAn-PAUL SÉnÉCAL

Longueuil

1. Cassell's, New F.-E., E.-F. Dictionary, p. 223.

2. Ibid., p. 657 .

3. Larousse, Dictionnaire encyclopédique pour tous, p. 924

4. Hoyer-Kreuter, Dictionnaire technique, p. 586. 